\title{
Plasma concentrations of gastrin and somatostatin after breast feeding in 4 day old infants
}

\author{
G MARCHINI, ${ }^{*} \mathrm{~J}$ WINBERG, ${ }^{*} \mathrm{~K}$ UVNÄS-MOBERG $\dagger$ \\ *Department of Paediatrics, Karolinska Hospital, and †Department of Pharmacology, Karolinska Institute, \\ Stockholm, Sweden
}

SUMMARY The plasma concentrations of gastrin and somatostatin were measured by radioimmunoassay before and after breast feeding in healthy 4 day old infants who had been born at full term. The mean (SD) concentrations of gastrin and somatostatin before breast feeding were 120 (30) pmol/l and 35 (12) pmol/l, respectively. Breast feeding in these infants was not followed by increased concentrations of gastrin and somatostatin in peripheral blood. High preprandial peptide concentrations, as seen during the neonatal period may limit the further release of peptide after feeding.

The pattern of the release of gastrin induced by feeding changes during the neonatal period. The plasma gastrin concentration increases in response to the first feed of breast milk ${ }^{1}$ or formula milk ${ }^{2}$ in newborn infants aged 2-6 hours. No such increase, however, has been seen after subsequent feeds during the first week of life. ${ }^{3}$ A possible explanation of why the gastrin concentration does not rise after feeding during this period could be the pressure of high concentrations of somatostatin, which is known to inhibit the release of gastrin. We therefore measured the plasma concentrations of gastrin and somatostatin before and after breast feeding in healthy 4 day old infants who had been born at full term.

\section{Patients and methods}

Thirty eight healthy infants ( 23 boys and 15 girls) were studied with the approval of the local ethical committee and the consent of the parents. All the babies had been born at full term after uncomplicated pregnancies. Their mean (SD) gestational age was 39 (1) weeks and birth weight 3468 (397) g. All infants were exclusively breast fed. Blood samples for determination of gastrin and somatostatin concentrations were collected at a mean (SD) of 4 (1) days of age. Thirty two infants were breast fed between 9 and 12 am and six between noon and $3 \mathrm{pm}$. This feed took place 3 (1) hours after the preceding feed and according to the mother was demanded by the infant. The infants were allowed to suck to satiety. The mean (SD) duration of feed was 25 (10) minutes and the amount of milk ingested, calculated by weighing 19 infants, was $55(30) \mathrm{ml}$.

Samples of $1.5 \mathrm{ml}$ of venous blood were drawn from the backs of the hands with open needles as part of routine metabolic screening. The samples were collected in one group of infants $(n=12)$ before and 10 minutes after feeding, in a second group $(n=14)$ before and 30 minutes after feeding, and in a third group $(n=12)$ before and 60 minutes after feeding. Bloods samples were collected in ice cold plastic tubes containing $10 \mathrm{IU}$ heparin and $500 \mathrm{KIE}$ aprotinin $/ \mathrm{ml}$ blood and centrifuged at $4{ }^{\circ} \mathrm{C}$ within 30 minutes of collection. The plasma samples were stored at $-20^{\circ} \mathrm{C}$ until analysed for concentrations of gastrin and somatostatin.

Gastrin concentrations were determined by radioimmunoassay using antiserum $2604 .^{4}$ as described by Nilsson. These antibodies recognise gastrin-17 and gastrin-34 as well as sulphated and unsulphated forms of gastrin with the same potency. Somatostatin concentrations were measured by the assay described by Efendic $e t a l^{5}$ after separation from large plasma proteins with SEP-PAK C18 cartridges (Water Associates Inc).

Data are given as mean (SD). Statistical analyses were by Student's $t$ test. Correlations between variables were analysed by simple regression analysis.

\section{Results}

Preprandial plasma gastrin $(n=34)$ and somatostatin 
$(\mathrm{n}=38)$ concentrations were $120(30) \mathrm{pmol} / \mathrm{l}$ and 35

(12) $\mathrm{pmol} / \mathrm{l}$, respectively. These were not related to postnatal age nor to the time intervals since the preceding meal. No significant rises occurred post- prandially in gastrin or somatostatin concentrations (figs 1 and 2). There was no association between gastrin and somatostatin concentrations either before or after breast feeding.
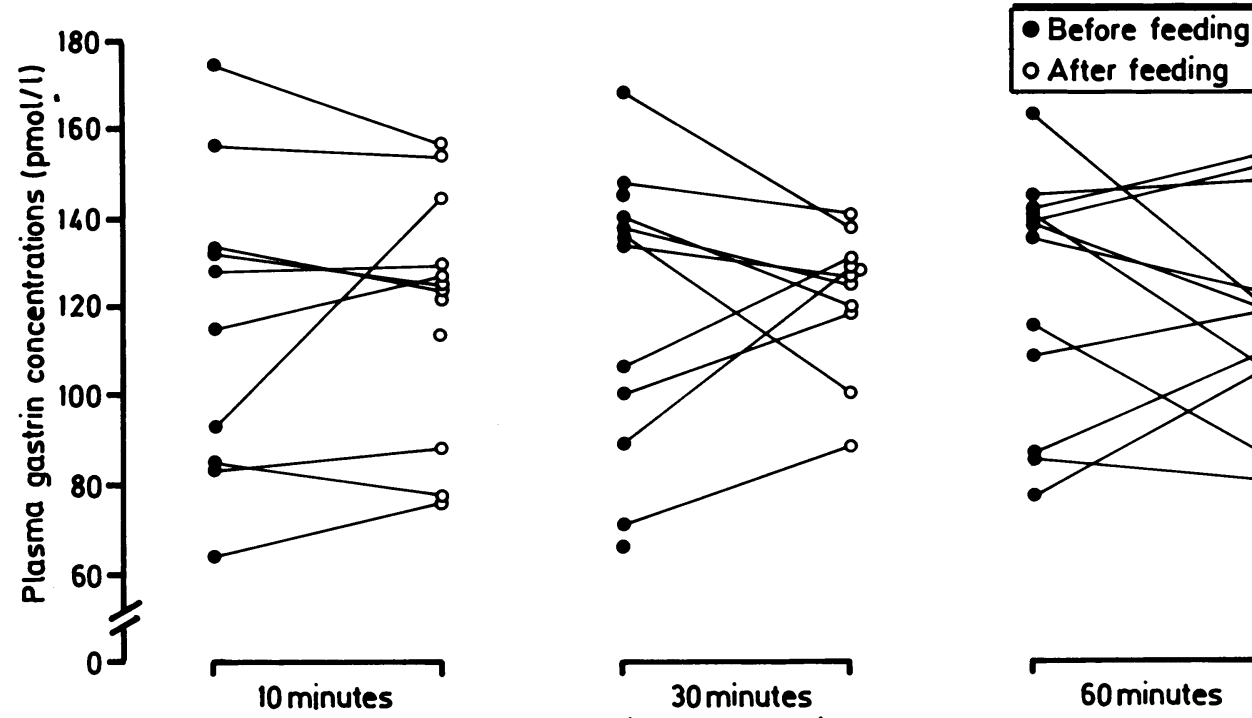

\section{- After feeding}
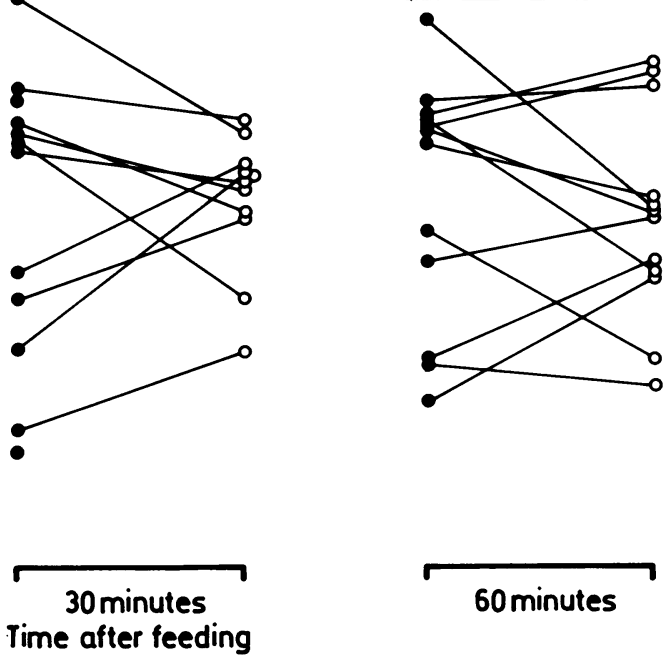

60 minutes

Fig 1 Individual plasma gastrin concentrations in three groups of infants before and after breast feeding.
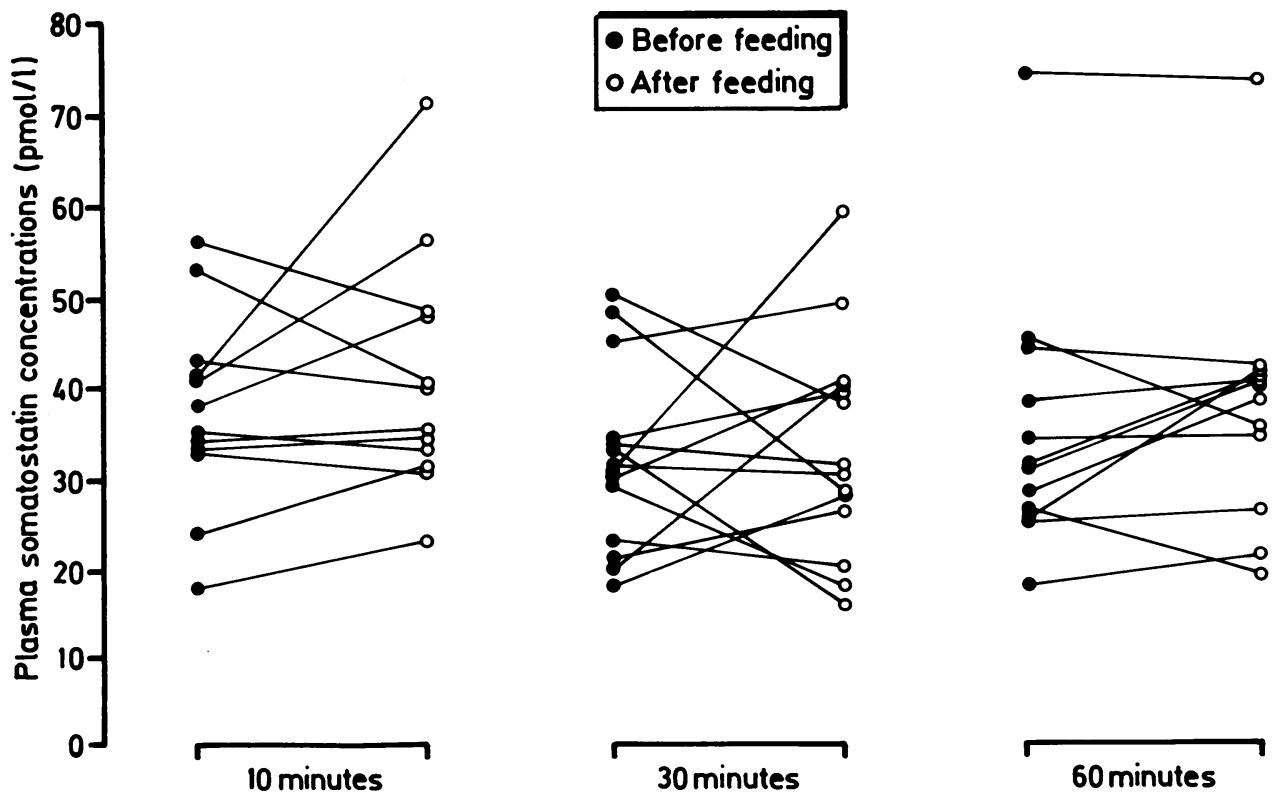

30 minutes

Time after feeding

Fig 2 Individual plasma somatostatin concentrations in three groups of infants before and after breast feeding. 


\section{Discussion}

We found no increase in gastrin concentrations after breast feeding in 4 day old infants. This is in accordance with previous studies performed at a similar postnatal age that reported no change in the concentration of gastrin after breast feeding or bottle feeding in infants born at full term, ${ }^{6}$ or after tube feeding in infants born prematurely. ${ }^{3}$

The absence of an increase in gastrin induced by feeding in infants has been ascribed to the high basal concentration of gastrin that is present during the neonatal period. ${ }^{3}$ The first feed given to newborn infants is followed by a postprandial increase in plasma gastrin concentration, ${ }^{12}$ though no such response is seen on the second or the sixth days, by which times basal plasma gastrin concentrations have increased 10 fold compared with the concentrations before the first feed. ${ }^{67}$ The comparative hypergastrinaemia could also partly explain why infants do not respond by secreting acid after being given pentagastrin or histamine during the neonatal period $^{89}$ or why non-nutritive sucking (a stimulus that has been suggested as triggering the release of other vagally controlled peptides such as insulin), failed to influence plasma gastrin concentrations in newborn infants. ${ }^{10}$

Because gastrin exerts trophic effects on the gastric mucosa, ${ }^{11}$ the rapid growth of the stomach that occurs in mammals during the first week of life $^{12}$ could be associated with the high gastrin concentrations during the neonatal period.

Circulating somatostatin is principally derived from the stomach ${ }^{13}$ and gastric somatostatin is produced partly in antral cells that are in open contact with the gastric lumen that are sensitive to intragastric $\mathrm{pH} .{ }^{14}$ Somatostatin from these cells exerts an inhibitory effect on the release of gastrin by local paracrine mechanisms. Most gastric somatostatin cells are found in the corporeal mucosa and here the peptide is associated with the regulation of the secretion of gastric acid from the parietal cells. Gastric somatostatin is released in response to nutrients in the stomach and is influenced by vagal nerve activity and antral $\mathrm{pH}$. $^{13}$

In the present study basal concentrations of somatostatin were in the same range as those described in premature babies and they were therefore high when compared with preprandial concentrations in adults. ${ }^{15}$ We did not find any significant change in somatostatin concentrations before or after breast feeding. This is in contrast to the results of Sann et al, who found that tube feeding in 2 day old premature infants induced a decrease in postprandial somatostatin concentrations. ${ }^{15} \mathrm{~A}$ comparison between their results and ours, however, is difficult because gestational age, postnatal age, and mode of feeding were different in the two studies.

The high plasma concentrations of somatostatin are likely to reflect enhanced secretion of somatostatin by the gastric mucosa. Because somatostatin inhibits the release of gastrin, an increase in the release of antral somatostatin may contribute to the unresponsiveness of the gastrin cells during the first week of life. Furthermore, as somatostatin inhibits secretion of acid from the parietal cells, a high rate of secretion of somatostatin in the corporeal mucosa might explain (in addition to the increased plasma gastrin concentrations) why pentagastrin and histamine fail to induce secretion of acid during the neonatal period. ${ }^{9}{ }^{10}$ In newborn and tube fed preterm infants a substantial release of somatostatin into the gastric lumen occurs when the intragastric $\mathrm{pH}$ is low. ${ }^{16} 17$ This somatostatin is probably derived from the antral somatostatin cells. ${ }^{13}$ Because the present data show that circulating somatostatin concentrations are not increased after breast feeding, either there are no changes caused by feeding in the rate of secretion of antral somatostatin or, if there are, the responses are not reflected in changes in the circulating somatostatin concentrations of 4 day old infants.

In conclusion, this study shows that breast feeding in 4 day old infants is not followed by increased gastrin or somatostatin concentrations in peripheral blood. We suggest that the high plasma concentrations of the two peptides before feeding reflect a high degree of stimulation of the gastrin and somatostatin producing cells (even under basal conditions) during a period of life when intake of nutrients is high, and the rate of growth increases rapidly.

We thank Professor J Rehfeld for the antiserum 2604. The study was supported by the First of May Flower Annual Campaign for Childrens' Health, the Foundations of Mjölkdroppen and Samariten, and the Insurance Company Förenade Liv. Mrs Karin Bygdeman gave skilful assistance in the collection of the blood samples.

\section{References}

1 Aynsley-Green A, Lucas A, Bloom SR. The effect of feeds of differing composition on entero-insular hormone secretion in the first hours of life in human neonates. Acta Paediatr Scand 1979;68:265-70.

2 Von Berger L, Henrichs I, Raptis S, et al. Gastrin concentration in plasma of the neonate at birth and after the first feed. Pediatrics 1976;58:264-7.

3 Lucas A, Bloom SR, Aynsley-Green A. Development of gut hormone responses to feeding in neonates. Arch Dis Child 1980;55:678-82

4 Nilsson G. Increased plasma gastrin levels in connection with inhibitin of gastric acid response to sham feeding, following bulbar perfusion with acid in dogs. Scand $J$ Gastroenterol 1975;10:273-7.

5 Efendic S, Enzmann F, Nylen A, Uvnäs-Wallensten K. Sulphonylurea (glibenclamide) enhances somatostatin and 
Plasma concentrations of gastrin and somatostatin after breast feeding in 4 day old infants 1221

inhibits glucagon release induced by arginin. Acta Physiol Scand 1980;108:231-3.

${ }^{6}$ Lucas A, Blackburn AM, Aynsley-Green A, Sarson DL, Adrian TE, Bloom SR. Breast vs bottle: endocrine responses are different with formula feeding. Lancet 1980;i:1267-9.

7 Lucas A, Adrian TE, Christofides N, Bloom SR, AynsleyGreen A. Plasma motilin, gastrin and enteroglucagon and feeding in the human newborn. Arch Dis Child 1980;55:673-7.

8 Euler A, Byrne W, Meis PJ, Leake R, Ament A. Basal and pentagastrin-stimulated acid secretion in newborn human infants. Pediatr Res 1979;13:36-7.

9 Agunod M, Yamaguchi N, Lopez R, Luhby L, Jerzy-Glass G. Correlative study of hydrochloric acid, pepsin, and intrinsic factor secretion in newborns and infants. American Journal of Digestive Diseases 1969;14:400-14.

10 Marchini G, Lagercrantz H, Feugerberg Y, Winberg J, UvnäsMoberg $\mathrm{K}$. The effect of non-nutritive sucking on plasma insulin, gastrin and somatostatin levels in infants. Acta Paediatr Scand 1987;76:573-8.

11 Johnson LR. The trophic action of gastrointestinal hormones. Gastroenterology 1976;70:278-88.

12 Widdowson EM, Colombo VE, Artavanis CA. Changes in the organs of pigs in response to feeding for the first $24 \mathrm{~h}$ after birth. Biol Neonate 1976;78:272-81.
${ }^{13}$ Gutniak M, Grill W, Wiechel K-L, Efendic S. Basal and meal induced somatostatin-like immunoreactivity in healthy subjects and in IDDM and totally pancreatectomized patients. Diabetes 1987;36:802-7.

14 Uvnäs-Moberg K. Gastrointestinal hormones and pathophysiology of functional disorders. Scand J Gastroenterol 1987;22(suppl 128):138-46.

15 Sann L, Chayvialle JA, Descos F. Plasma somatostatin concentration in the preterm neonate. Pediatrics 1982;139:148-50.

16 Widström AM, Christensson K, Ransjö-Arvidson A-B, Matthiesen A-S, Uvnäs-Moberg K. Gastric suction in newborn infants $\mathrm{pH}$, volume and levels of gastrin and somatostatin-like immunoreactivity in gastric aspirates of newborn infants. Acta Paediatr Scand 1988;77:502-8.

17 Widström A-M, Marchini G, Matthiesen A-S, Werner S, Winberg J, Uvnäs Moberg K. Non-nutritive sucking in tube-fed infants: effects on gastric motility and gastric contents of somatostatin. J Pediatr Gastroenterol Nutr; 7:517-23.

Correspondence to Dr G Marchini, Department of Paediatrics, Karolinska Hospital, Box 60140, Stockholm, Sweden.

Accepted 22 February 1988 